Pacific Journal of Mathematics

ON THE REVERSE WEAK TYPE INEQUALITY FOR THE
HARDY MAXIMAL FUNCTION AND THE WEIGHTED

KenNeth F. ANDERSEN AND Wo-SANG YounG 


\title{
ON THE REVERSE WEAK TYPE INEQUALITY FOR THE HARDY MAXIMAL FUNCTION AND THE WEIGHTED CLASSES $L(\log L)^{k}$
}

\author{
KENNETH F. ANDERSEN AND Wo-SANG Young
}

Muckenhoupt has given a necessary and sufficient condition to be satisfied by the weight functions $U$ and $V$ in order that the HardyLittlewood maximal function $M f$ should satisfy a weighted weak type $(1,1)$ inequality. In this note, conditions on the weight functions $U$ and $V$ are given in order that the sense of this inequality may be reversed. This is then applied to give conditions which ensure that the integrability of $M f$ with respect to a weight implies that $f$ belongs to a weighted Zygmund class $L \log L$, thus extending a result of Stein. Analogous results related to the strong maximal function and the classes $L(\log L)^{k}$ are also given. These extend certain results of Favo, Gatto and Gutiérrez.

If $f$ is locally integrable on $R^{n}$, the Hardy-Littlewood maximal function $M f$ is defined by

$$
(M f)(x)=\sup |Q|^{-1} \int_{Q}|f|
$$

where the supremum is taken over all cubes $Q$ containing $x$. Here and henceforth, by "cube" we shall always mean "cube with sides parallel to the co-ordinate axis". As usual, $|E|$ denotes the Lebesgue measure of the measurable set $E$, and more generally if $U(x) \geq 0$ is defined on $E$ we write $|E|_{U}=\int_{E} U(x) d x$. If $Q$ is a given cube, $R Q$ denotes the cube concentric with $Q$ but with side $R$ times as long. $Q_{0}$ will denote a fixed but arbitrary cube in $R^{n}$. Our first result is the following theorem.

THEOREM 1. Suppose the non-negative weight functions $U$ and $V$ are defined on $Q_{0}$. If there is a constant $C$ depending only on $U$ and $V$ such that

$$
\frac{|Q|_{U}}{|Q|} \geq C \underset{x \in Q}{\operatorname{ess} \sup } V(x) \text { for all cubes } Q \subset Q_{0},
$$

then

(2) $\left|\left\{x \in Q_{0}:(M f)(x)>\lambda\right\}\right|_{U} \geq C 2^{-n} \lambda^{-1} \int_{\{x: f(x)>\lambda\}} f(x) V(x) d x$ 
holds for all non-negative $f$ supported on $Q_{0}$ with $\int_{Q_{0}} f<\infty$ and all $\lambda \geq \lambda_{0}$ $=\left|Q_{0}\right|^{-1} \int_{Q_{0}} f$. Conversely, if (2) holds for some constant $C$ independent of all $f$ which are characteristic functions of measurable sets $E \subset Q_{0}$ with $|E|>0$ and for all $\lambda \geq \lambda_{0}=\left|Q_{0}\right|^{-1}|E|$, then

$$
\frac{\left|(2 Q) \cap Q_{0}\right|_{U}}{|Q|} \geq C 4^{-n} \underset{x \in Q}{\operatorname{ess} \sup } V(x)
$$

for all cubes $Q \subset Q_{0}$.

Corollary 1. Let $U(x) \geq 0, V(x) \geq 0$ be defined on $R^{n}$. If there is a constant $C$ depending only on $U, V$ such that

$$
\frac{|Q|_{U}}{|Q|} \geq C \underset{x \in Q}{\operatorname{ess} \sup } V(x) \text { for all cubes } Q \subset R^{n}
$$

then

(5) $\left|\left\{x \in R^{n}:(M f)(x)>\lambda\right\}\right|_{U} \geq C 2^{-n} \lambda^{-1} \int_{\{x: f(x)>\lambda\}} f(x) V(x) d x$

holds for all non-negative $f$ and all $\lambda>0$. Conversely, if (5) holds for all $f$ which are characteristic functions of measurable sets $E \subset R^{n}$ with $0<|E|<$ $\infty$ and all $\lambda>0$, then

$$
\frac{|2 Q|_{U}}{|Q|} \geq C 4^{-n} \underset{x \in Q}{\operatorname{ess} \sup } V(x) \quad \text { for all cubes } Q \subset R^{n} .
$$

If $U$ satisfies the doubling condition

$$
|2 Q|_{U} \leq C|Q|_{U} \text { for all cubes } Q
$$

then (6) shows that (4) is both necessary and sufficient for (5). Observe that the example $U(x)=1$ on $R^{n}-Q_{0}, U(x)=\infty$ otherwise, satisfies (4) with $U=V$ but does not satisfy the doubling condition. On the other hand, if $U$ is locally integrable and satisfies (4) with $U=V$ then $U$ necessarily satisfies the doubling condition. To see this, note that (4) is equivalent to

$$
\frac{|Q|_{U}}{|Q|} \geq C \frac{|E|_{V}}{|E|} \quad \text { for all measurable } E \subset Q \text { with }|E|>0
$$

so that with $U=V$ it follows that $U$ satisfies the $A_{\infty}$ condition of Muckenhoupt [2] and hence also the doubling condition. 
The inequality (5) may be viewed as a reverse of the weak type $(1,1)$ inequality

$$
\left|\left\{x \in R^{n}:(M f)(x)>\lambda\right\}\right|_{U} \leq C \lambda^{-1} \int_{\{x: f(x)>\lambda / 2\}} f(x) V(x) d x
$$

which holds if and only if $U, V$ satisfy the $A_{1}$ condition of Muckenhoupt [3], namely, $|Q|_{U} /|Q| \leq \mathrm{Cess}_{\inf _{x \in Q}} V(x)$ for all cubes $Q$. Restricting to the case $U=V$, the $A_{1}$ condition implies that $U$ satisfies the doubling condition, and hence the weak type inequality and its reverse both hold in this case if and only if there are positive constants $c_{1}$ and $c_{2}$ such that $c_{1} \leq U(x) \leq c_{2}$ for almost all $x \in R^{n}$.

If $U(x)^{-1}$ satisfies the $A_{1}$ condition, Hölder's inequality shows that (4) holds with $U=V$. The functions $U(x)=V(x)=|x|^{\alpha}, \alpha \geq 0$, provide further examples that satisfy (4).

Theorem 1 may be used to prove the following result.

THEOREM 2. Suppose $f(x) \geq 0$ is supported on $Q_{0}$ and that there is a constant $C>0$ such that the weight functions $U(x) \geq 0, V(x) \geq 0$ satisfy

$$
\frac{|Q|_{U}}{|Q|} \geq C \underset{x \in Q}{\operatorname{ess} \sup } V(x) \quad \text { for all cubes } Q \subset Q_{0}
$$

Then

$$
\int_{Q_{0}}(M f)(x) U(x) d x<\infty
$$

implies

$$
\int_{Q_{0}}\left[f(x) \log ^{+} f(x)\right] V(x) d x<\infty .
$$

Corollary 1 and Theorem 2 generalize some results of Stein [4] who considered the unweighted case, $U(x) \equiv V(x) \equiv 1$.

Let $1 \leq i \leq n$ and let $M_{l}$ denote the Hardy-Littlewood maximal function in the $i$ th variable, that is

$$
\left(M_{\imath} f\right)(x)=\underset{a, b>0}{\operatorname{ess} \sup _{a}}(a+b)^{-1} \int_{-a}^{b}\left|f\left(x_{1}, \ldots, x_{t-1}, x_{t}+t, x_{t+1}, \ldots, x_{n}\right)\right| d t
$$

where $x=\left(x_{1}, \ldots, x_{n}\right)$. The following generalize certain results of Favo, Gatto and Gutiérrez [1] who considered the unweighted case, $U(x) \equiv 1$. 
THEOREM 3. Let $U(x) \geq 0$ be defined on $R^{n}$ and let $k$ be a fixed integer, $1 \leq k \leq n$. If there is a constant $C$ depending only on $U$ and $k$ such that for each $i, 1 \leq i \leq k$,

$$
\begin{aligned}
(a+b)^{-1} \int_{-a}^{b} U\left(x_{1}, \ldots, x_{i-1}, x_{i}+t, x_{i+1}, \ldots, x_{n}\right) d t & \\
& \geq C \underset{-a<t<b}{\operatorname{ess} \sup _{-}} U\left(x_{1}, \ldots, x_{t-1}, x_{i}+t, x_{i+1}, \ldots, x_{n}\right)
\end{aligned}
$$

for all $a, b>0$ and almost all $x \in R^{n}$, then

$$
\begin{aligned}
\mid\left\{x \in R^{n}:\right. & \left.\left(M_{k} \cdots M_{1} f\right)(x)>\lambda\right\}\left.\right|_{U} \\
\geq & \frac{2^{-k} C^{k}}{(k-1) ! \lambda} \int_{\{x: f(x)>\lambda\}} f(x)\left[\log ^{+}\left(\frac{f(x)}{\lambda}\right)\right]^{k-1} U(x) d x
\end{aligned}
$$

holds for all $\lambda>0$ and all $f \geq 0$.

COROLlary 2. With the same hypothesis as Theorem 3 and $C>0$, if $\left(M_{k} \cdots M_{1} f\right)(x) \rightarrow 0$ as $|x| \rightarrow \infty$ and $\int_{E}\left(M_{k} \cdots M_{1} f\right)(x) U(x) d x<\infty$ for every bounded set $E \subset R^{n}$, then

$$
\int_{R^{n}}|f(x)|\left[\log ^{+}|f(x)|\right]^{k} U(x) d x<\infty .
$$

Proof of Theorem 1. First we will prove that (1) implies (2). Since $\lambda \geq \lambda_{0}$ and $f$ is supported on $Q_{0}, \lambda \geq\left|Q_{0}\right|^{-1} \int_{R^{n}} f$ so the Calderón-Zygmund decomposition [5, Theorem 4, p. 17] shows that there are pairwise disjoint cubes $\left\{Q_{j}\right\}$ satisfying

$$
\begin{gathered}
\cup Q_{j} \subset Q_{0}, \\
\lambda<\left|Q_{J}\right|^{-1} \int_{Q_{j}} f \leq 2^{n} \lambda
\end{gathered}
$$

and

$$
f(x) \leq \lambda \quad \text { if } x \notin \bigcup Q_{j} .
$$

The definition of $M f$ and (11) shows that $(M f)(x)>\lambda$ if $x \in Q_{J}$ and then (10) yields $\cup Q_{j} \subset\left\{x \in Q_{0}:(M f)(x)>\lambda\right\}$ so that

$$
\left|\left\{x \in Q_{0}:(M f)(x)>\lambda\right\}\right|_{U} \geq \sum_{j}\left|Q_{j}\right|_{U}
$$


Now from (11) and hypothesis (1) it follows that

$$
\begin{aligned}
& \sum_{j}\left|Q_{j}\right|_{U} \geq 2^{-n} \lambda^{-1} \sum_{j}\left|Q_{j}\right|_{U}\left(\left|Q_{j}\right|^{-1} \int_{Q_{j}} f(x) d x\right) \\
& \geq 2^{-n} \lambda^{-1} C \sum_{j}\left(\underset{x \in Q_{j}}{\operatorname{ess} \sup } V(x)\right)\left(\int_{Q_{j}} f(x) d x\right) \\
& \geq 2^{-n} \lambda^{-1} C \sum_{j} \int_{Q_{j}} f(x) V(x) d x=2^{-n} \lambda^{-1} C \int_{\cup Q_{j}} f(x) V(x) d x,
\end{aligned}
$$

while from (12) $\cup Q_{j} \supset\left\{x \in R^{n}: f(x)>\lambda\right\}$ so that

$$
\int_{\cup Q,} f(x) V(x) d x \geq \int_{\{x: f(x)>\lambda\}} f(x) V(x) d x .
$$

Thus (1) implies (2).

Conversely, let $Q \subset Q_{0}$ be given. Let $\varepsilon>0$ and select $E_{\varepsilon} \subset Q$ with $0<\left|E_{\varepsilon}\right|<2^{-n}|Q|$ so that $V(x)>$ ess $\sup _{t \in Q} V(t)-\varepsilon$ for $x \in E_{\varepsilon}$. Then with $f(x)=1$ if $x \in E_{\varepsilon}, f(x)=0$ otherwise, and $\lambda=2^{n}\left|E_{\varepsilon}\right| /|Q|$, elementary geometry shows that $(M f)(x) \leq \lambda$ if $x \notin 2 Q$. Thus (2) yields

$$
\begin{aligned}
\left|(2 Q) \cap Q_{0}\right|_{U} & \geq\left|\left\{x \in Q_{0}:(M f)(x)>\lambda\right\}\right|_{U} \\
& \geq C 4^{-n} \frac{|Q|}{\left|E_{\varepsilon}\right|} \int_{E_{\varepsilon}} V(x) d x \geq C 4^{-n}|Q|(\underset{t \in Q}{\operatorname{ess} \sup } V(t)-\varepsilon) .
\end{aligned}
$$

Since $\varepsilon$ is arbitrary we obtain (3). This proves Theorem 1 .

Proof of Corollary 1. The proof that (5) implies (6) is similar to that used to prove that (2) implies (3) and is therefore omitted. Now if (4) holds and $f(x) \geq 0$, let $Q_{0}$ be a fixed cube and let $f_{t}(x)=f(x)$ if $f(x) \leq t$ and $x \in t Q_{0}, f_{t}(x)=0$ otherwise. For $\lambda>0$, Theorem 1 yields

$$
\left|\left\{x \in R Q_{0}:\left(M f_{t}\right)(x)>\lambda\right\}\right|_{U} \geq C 2^{-n} \lambda^{-1} \int_{\left\{x: f_{t}(x)>\lambda\right\}} f_{t}(x) V(x) d x
$$

provided $R$ satisfies $\left|R Q_{0}\right|^{-1} \int_{R^{n}} f_{t} \leq \lambda$ and $R \geq t$. Note that $f_{t}(x) \uparrow f(x)$ and $\left(M f_{t}\right)(x) \uparrow(M f)(x)$ as $t \rightarrow \infty$. Hence (5) follows from (14) by the monotone convergence theorem, letting $R \rightarrow \infty$ first, then $t \rightarrow \infty$. This proves the Corollary.

Proof of Theorem 2. Assume that $V(x)>0$ on a set of positive measure in $Q_{0}$ for otherwise there is nothing to prove. Then (7) shows that $\left|Q_{0}\right|_{U}>0$. Hence, if $f(x) Z 0$ a.e. then $(M f)(x) \geq\left|Q_{0}\right|^{-1} \int_{Q_{0}} f>0$ for 
$x \in Q_{0}$ and the hypothesis $\int_{Q_{0}}(M f)(x) U(x) d x<\infty$ implies that $f$ and $U$ are integrable on $Q_{0}$, and in view of (7), $V$ is also. Thus it suffices to show that

$$
\int_{\left\{x: f(x)>\lambda_{0}\right\}} f(x) \log \left(\frac{f(x)}{\lambda_{0}}\right) V(x) d x<\infty
$$

where $\lambda_{0}=\left|Q_{0}\right|^{-1} \int_{Q_{0}} f$.

Fubini's Theorem shows that the left side of (15) is equal to

$$
\int_{\lambda_{0}}^{\infty} \frac{d \lambda}{\lambda} \int_{\{x: f(x)>\lambda\}} f(x) V(x) d x
$$

and Theorem 1 shows that this is bounded above by

$$
C^{-1} 2^{n} \int_{\lambda_{0}}^{\infty}\left|\left\{x \in Q_{0}:(M f)(x)>\lambda\right\}\right|_{U} d \lambda .
$$

This integral is bounded by

$$
\int_{0}^{\infty}\left|\left\{x \in Q_{0}:(M f)(x)>\lambda\right\}\right|_{U} d \lambda=\int_{Q_{0}}(M f)(x) U(x) d x
$$

so we obtain (15) and the theorem is proved.

Proof of Theorem 3. Observe first that for any fixed $i, 1 \leq i \leq k$, Corollary 1 and (8) show that

$$
\int_{\left\{x_{l} \in R^{\prime}:\left(M_{l} f\right)(x)>\lambda\right\}} U(x) d x_{l} \geq \frac{2^{-1} C}{\lambda} \int_{\left\{x_{l}: f(x)>\lambda\right\}} f(x) U(x) d x_{l} .
$$

Integrating this inequality over the remaining variables yields

$$
\left|\left\{x \in R^{n}:\left(M_{i} f\right)(x)>\lambda\right\}\right|_{U} \geq \frac{2^{-1} C}{\lambda} \int_{\{x: f(x)>\lambda\}} f(x) U(* x) d x .
$$

Now the proof proceeds by induction. As we have just proved, (9) holds with $k=1$. Assume that (9) holds for some $k, k \leq n-1$. Then (16) yields

$$
\begin{aligned}
\left|\left\{x \in R^{n}:\left(M_{k+1} \cdots M_{1} f\right)(x)>\lambda\right\}\right|_{U} & \\
& \geq \frac{2^{-1} C}{\lambda} \int_{\left\{x:\left(M_{k} \cdots M_{1} f\right)(x)>\lambda\right\}}\left(M_{k} \cdots M_{1} f\right)(x) U(x) d x \\
& \geq 2^{-1} C \int_{\left\{x:\left(M_{k} \cdots M_{1} g\right)(x)>1\right\}}\left(M_{k} \cdots M_{1} g\right)(x) U(x) d x
\end{aligned}
$$


where we have set $g(x)=f(x) / \lambda$ if $f(x)>\lambda$ and $g(x)=0$ otherwise. Now

$$
\begin{aligned}
\int_{\left\{x:\left(M_{k} \cdots M_{1} g\right)(x)>1\right\}}( & \left.M_{k} \cdots M_{1} g\right)(x) U(x) d x \\
& =\int_{0}^{\infty}\left|\left\{x:\left(M_{k} \cdots M_{1} g\right)(x)>\max (1, \alpha)\right\}\right|_{U} d \alpha \\
& \geq \int_{1}^{\infty}\left|\left\{x:\left(M_{k} \cdots M_{1} g\right)(x)>\alpha\right\}\right|_{U} d \alpha
\end{aligned}
$$

so that the inductive hypothesis shows this is bounded below by

$$
\begin{gathered}
\frac{2^{-k} C^{k}}{(k-1) !} \int_{1}^{\infty} \frac{d \alpha}{\alpha} \int_{\{x: g(x)>\alpha\}} g(x)\left[\log \left(\frac{g(x)}{\alpha}\right)\right]^{k-1} U(x) d x \\
=\frac{2^{-k} C^{k}}{k !} \int_{\{x: g(x)>1\}} g(x)[\log g(x)]^{k} U(x) d x \\
=\frac{2^{-k} C^{k}}{k ! \lambda} \int_{\{x: f(x)>\lambda\}} f(x)\left[\log \left(\frac{f(x)}{\lambda}\right)\right]^{k} U(x) d x .
\end{gathered}
$$

Thus we have (9) for $k+1$ and the proof is complete.

Proof of Corollary 2. Since $\left(M_{k} \cdots M_{1} f\right)(x) \rightarrow 0$ as $|x| \rightarrow \infty$ the set $E=\left\{x:\left(M_{k} \cdots M_{1} f\right)(x) \geq 1\right\}$ is bounded. Thus, Theorem 3 shows

$$
\begin{aligned}
\infty & >\int_{E}\left(M_{k} \cdots M_{1} f\right)(x) U(x) d x \geq \int_{1}^{\infty}\left|\left\{x:\left(M_{k} \cdots M_{1} f\right)(x)>\lambda\right\}\right|_{U} d \lambda \\
& \geq \frac{2^{-k} C^{k}}{(k-1) !} \int_{1}^{\infty} \frac{d \lambda}{\lambda} \int_{\{x: f(x)>\lambda\}} f(x)\left[\log \left(\frac{f(x)}{\lambda}\right)\right]^{k-1} U(x) d x \\
& =\frac{2^{-k} C^{k}}{k !} \int_{R^{n}} f(x)\left[\log ^{+} f(x)\right]^{k} U(x) d x
\end{aligned}
$$

where we have used Fubini's Theorem to obtain the last equality. This proves the Corollary.

\section{REFERENCES}

[1] N. A. Favo, E. A. Gatto and C. Gutiérrez, On the strong maximal function and Zygmund's class $L\left(\log ^{+} L\right)^{n}$, Studia Math., 69 (1980), 155-158.

[2] B. Muckenhoupt, The equivalence of two conditions for weight functions, Studia Math., 49 (1974), 101-106. 
[4] E. M. Stein, Note on class L log L, Studia Math., 32 (1969), 305-310.

[5] Singular Integrals and the Differentiability Properties of Functions, Princeton University Press, 1970.

Received June 11, 1982. Research of the first author was supported in part by NSERC grant A-8185. The second author's research was supported in part by NSERC grant A-5165.

UNIVERSITy OF AlBERTA

EDMONTON, T6G 2G1 CANADA 


\title{
PACIFIC JOURNAL OF MATHEMATICS EDITORS
}

\author{
Donald BabBITT (Managing Editor) \\ University of California \\ Los Angeles, CA 90024 \\ Hugo Rossi \\ University of Utah \\ Salt Lake City, UT 84112 \\ C. C. Moore and Arthur Ogus \\ University of California \\ Berkeley, CA 94720
}

\author{
J. Dugundu \\ Department of Mathematics \\ University of Southern California \\ Los Angeles, CA 90089-1113
}

R. FINN and H. SAMELSON

Stanford University

Stanford, CA 94305

\section{ASSOCIATE EDITORS}
R. ARENS
E. F. BECKENBACH
B. H. NeumanN
F. WolF
K. YosHIDA (1906-1982)

\section{SUPPORTING INSTITUTIONS}

\author{
UNIVERSITY OF ARIZONA \\ UNIVERSITY OF BRITISH COLUMBIA \\ CALIFORNIA INSTITUTE OF TECHNOLOGY \\ UNIVERSITY OF CALIFORNIA \\ MONTANA STATE UNIVERSITY \\ UNIVERSITY OF NEVADA, RENO \\ NEW MEXICO STATE UNIVERSITY \\ OREGON STATE UNIVERSITY
}

\author{
UNIVERSITY OF OREGON \\ UNIVERSITY OF SOUTHERN CALIFORNIA \\ STANFORD UNIVERSITY \\ UNIVERSITY OF HAWAII \\ UNIVERSITY OF TOKYO \\ UNIVERSITY OF UTAH \\ WASHINGTON STATE UNIVERSITY \\ UNIVERSITY OF WASHINGTON
}

The Supporting Institutions listed above contribute to the cost of publication of this Journal, but they are not owners or publishers and have no responsibility for its content or policies.

Mathematical papers intended for publication in the Pacific Journal of Mathematics should be in typed form or offset-reproduced (not dittoed), double spaced with large margins. Please do not use built up fractions in the text of the manuscript. However, you may use them in the displayed equations. Underline Greek letters in red, German in green, and script in blue. The first paragraph must be capable of being used separately as a synopsis of the entire paper. In particular it should contain no bibliographic references. Please propose a heading for the odd numbered pages of less than 35 characters. Manuscripts, in triplicate, may be sent to any one of the editors. Please classify according to the scheme of Math. Reviews, Index to Vol. 39. Supply name and address of author to whom proofs should be sent. All other communications should be addressed to the managing editor, or Elaine Barth, University of California, Los Angeles, California 90024.

There are page-charges associated with articles appearing in the Pacific Journal of Mathematics. These charges are expected to be paid by the author's University, Government Agency or Company. If the author or authors do not have access to such Institutional support these charges are waived. Single authors will receive 50 free reprints; joint authors will receive a total of 100 free reprints. Additional copies may be obtained at cost in multiples of 50 .

The Pacific Journal of Mathematics is issued monthly as of January 1966. Regular subscription rate: $\$ 132.00$ a year (6 Vol., 12 issues). Special rate: $\$ 66.00$ a year to individual members of supporting institutions.

Subscriptions, orders for numbers issued in the last three calendar years, and changes of address should be sent to Pacific Journal of Mathematics, P.O. Box 969, Carmel Valley, CA 93924, U.S.A. Old back numbers obtainable from Kraus Periodicals Co., Route 100, Millwood, NY 10546.

The Pacific Journal of Mathematics ISSN 0030-8730 is published monthly by the Pacific Journal of Mathematics at P.O. Box 969, Carmel Valley, CA 93924. Application to mail at Second-class postage rates is pending at Carmel Valley, California, and additional mailing offices. Postmaster: Send address changes to Pacific Journal of Mathematics, P. O. Box 969, Carmel Valley, CA 93924.

PUBLISHED BY PACIFIC JOURNAL OF MATHEMATICS. A NON-PROFIT CORPORATION

Copyright $\odot 1984$ by Pacific Journal of Mathematics 


\section{Pacific Journal of Mathematics}

\section{Vol. 112, No. $2 \quad$ February, 1984}

Kenneth F. Andersen and Wo-Sang Young, On the reverse weak type inequality for the Hardy maximal function and the weighted classes

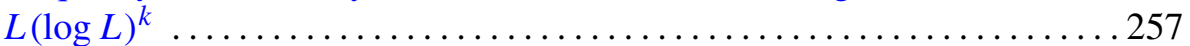

Richard Eugene Bedient, Double branched covers and pretzel knots ..... 265

Harold Philip Boas, Holomorphic reproducing kernels in Reinhardt

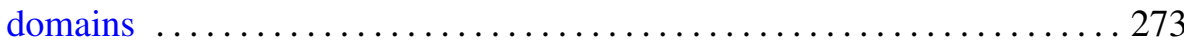

Janey Antonio Daccach and Arthur Gabriel Wasserman, Stiefel's theorem and toral actions ................................. 293

Michael Fried, The nonregular analogue of Tchebotarev's theorem ....... 303

Stanley Joseph Gurak, Minimal polynomials for circular numbers . . . . . . 313

Norimichi Hirano and Wataru Takahashi, Nonlinear ergodic theorems for an amenable semigroup of nonexpansive mappings in a Banach space . . 333

Jim Hoste, Sewn-up $r$-link exteriors . . . . . . . . . . . . . . . . . . . 347

Mohammad Ahmad Khan, The existence of totally dense subgroups in

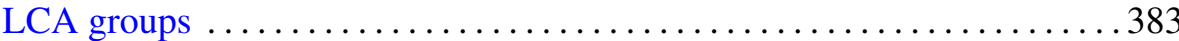

Mieczysław Kula, Murray Angus Marshall and Andrzej Sładek, Direct

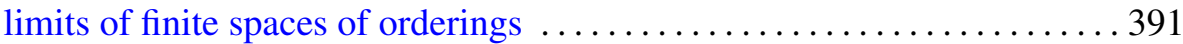

Luis Montejano Peimbert, Flat Hilbert cube manifold pairs ........... 407

Steven C. Pinault, An a priori estimate in the calculus of variations . . . . . 427

McKenzie Y. K. Wang, Some remarks on the calculation of Stiefel-Whitney classes and a paper of Wu-Yi Hsiang's

Brian Donald Wick, The calculation of an invariant for Tor . . 445

Wolfgang Wollny, Contributions to Hilbert's eighteenth problem 